Karl Kurbel

ERP und SCM 



\section{Karl Kurbel}

\section{ERP und SCM}

Enterprise Resource Planning und Supply Chain Management in der Industrie

9., überarb. und erw. Auflage

\section{DE GRUYTER \\ OLDENBOURG}


Autor

Prof. Dr. Karl Kurbel ist emeritierter Professor für Wirtschaftsinformatik an der Europa-Universität Viadrina in Frankfurt (Oder)

Die 8. Auflage trug noch den ausgeschriebenen Titel „Enterprise Resource Planning und Supply Chain Management in der Industrie“.

Bis zur 6. Auflage erschien das Werk unter dem Titel „Produktionsplanung und -steuerung im Enterprise Resource Planning und Supply Chain Management“

ISBN 978-3-11-070118-0

e-ISBN (PDF) 978-3-11-070120-3

e-ISBN (EPUB) 978-3-11-070148-7

Library of Congress Control Number: 2021933286

\section{Bibliografische Information der Deutschen Nationalbibliothek}

Die Deutsche Nationalbibliothek verzeichnet diese Publikation in der Deutschen Nationalbibliografie; detaillierte bibliografische Daten sind im Internet über http://dnb.dnb.de abrufbar.

(C) 2021 Walter de Gruyter GmbH, Berlin/Boston Umschlaggestaltung: Monty Rakusen / Cultura / Getty Images Satz: le-tex publishing services $\mathrm{GmbH}$, Leipzig Druck und Bindung: CPI books GmbH, Leck

www.degruyter.com 